\title{
Modern biopolyamide-based materials: synthesis and modification
}

\section{Paulina Radzik ${ }^{1} \cdot$ Agnieszka Leszczyńska $^{1} \mathbb{D} \cdot$ Krzysztof Pielichowski $^{1}$}

Received: 4 May 2018 / Revised: 30 November 2018 / Accepted: 12 February 2019 /

Published online: 9 March 2019

(C) The Author(s) 2019

\begin{abstract}
The wider use of renewable feedstock in structural applications, where high mechanical performance is required, can be achieved by the application of recently developed engineering biopolymers and their further modification by micro- and nanoparticles. In this review, we present the current state of the art of biopolyamide materials for structural and functional applications. The overview includes all stages of the manufacturing - from the synthesis of building blocks, through the synthesis of polymers and its physical modification, with special emphasis on the properties of the obtained engineering biocomposites as a final product of modern polymer technology. In the first part, the synthetic routes of bio-derived counterparts of common polyamides as well as specialty polymers with functional properties arising from the complex structure of biochemicals were exemplified. The development of environmentally friendly composites and nanocomposites based on biopolyamides and natural fillers, such as plant fibers or cellulosic nanofibers, was of particular interest due to preserved sustainable character of such materials.
\end{abstract}

Keywords Biopolyamides $\cdot$ Biocomposites $\cdot$ Natural fibers $\cdot$ Cellulose fibers

\section{Introduction}

Nowadays, there is a strong need to reduce the consumption of fossil resources in the production of polymeric materials. In order to provide a new generation of renewable, eco-friendly polymeric materials the classical polymer technology needs to be alternated in numerous fields, including production of raw materials, polymerization techniques, and physical modification of biopolymers. The term 'biopolymers' refers to materials partially or fully based on renewable substrates. Among various biopolymers, polyamides synthesized from biomass-derived monomers constitute an

Agnieszka Leszczyńska

aleszczynska@chemia.pk.edu.pl

1 Department of Chemistry and Technology of Polymers, Cracow University of Technology, ul. Warszawska 24, 31-155 Kraków, Poland 
interesting class with outstanding mechanical performance, such as high hardness, impact strength, and abrasion resistance, barrier and thermal properties, as well as good processability by, e.g., extrusion and injection molding. Recent research in the field of biopolyamides showed efforts to synthesise and apply monomers from renewable resources [1, 2], adapt enzyme technology for polymerization processes [3] and physically modify biopolyamides by compounding with natural reinforcing fillers and functional additives.

The areas of research and development reflect the specific market demands for biopolyamides as an engineering materials, where mechanical performance combined with functional properties is of major interest. With this respect, biopolyamide composites emerge as an attractive final materials that could be introduced in the machine, automotive, building, electrical and electronics, and consumer goods industries.

Currently, the main attention is paid to biopolyamide composites reinforced by plant fibers and cellulosic nanoparticles, since they offer improvement of mechanical performance without sacrificing the original renewable character of the material.

However, some other modifications imparting novel properties to biopolyamides are also investigated. Recently, Gorrasi et al. obtained composites containing thymol as a natural photostabilizer encapsulated in halloysite nanotubes. Both, the modulus and the photo-degradation time were increased for these composites [4]. The efficiency of natural compound introduced as a stabilizer was increased by using nanotechnology approach. Improvements of the biopolyamides mechanical and electrical behavior have recently been achieved as a result of incorporation of carbon nanoparticles. For instance, polyamide 6-based masterbatch containing carbon nanotubes was melt-mixed with a neat bioPA 4.10 and graphene nanoplatelets were added into biopolyamide 11 [5, 6]. Still, numerous alternative synthesis paths and composite materials need to be validated for biopolyamides in terms of properties and cost-effectiveness.

\section{Main building blocks for biopolyamides}

The development of bio-based feedstock is fundamental for the further progress in bioplastic production and is considered as a distinct and dynamically evolving field of chemical technology. New sustainable technologies of extraction and synthesis of a variety of biomass-derived monomers are reported in the literature [7, 8].

There are three main groups of monomers for the production of biopolyamides: (i) diamines and diacids undergoing polycondensation, where both monomers or only diacid come from renewable feedstock, (ii) amino-carboxylic acids capable for polycondensation (iii) lactams transformed into polyamides via ring-opening polymerization [9].

The main source of bio-based monomers for polyamides is castor oil, which makes up 40-60\% of the castor bean [10]. Castor oil, as most of natural feedstocks, has a complex composition. It consists of a mixture of saturated and unsaturated fatty acids, and the main component is $\mathrm{C} 18$ ricinoleic acid. Methods of castor oil extraction from beans include mechanical pressing, solvent extraction and a combination 
of these techniques [11, 12]. Further transformation of ricinoleic acid (1,2-hydroxyoctadec-9-enoic acid) leads to monomers useful in further synthesis of biopolyamides. Three functional groups in ricinoleic acid structure, namely hydroxyl, carboxyl and unsaturated bond are crucial for its further chemical derivatization [11, 13, 14]. They also make castor oil polar and therefore, soluble in alcohols and compatible with selected plasticizers $[11,15]$.

In Fig. 1 different routes leading to various types of biopolyamides are schematically showed [16].

Monomers used in biopolyamides synthesis can be obtained partially or fully from biomass. Currently, biomass-derived monomers with the highest industrial meaning for the synthesis of biopolyamides are 11-aminoundecanoic acid, 1,8-octanedicarboxylic acid, 1,10-decanediamine, adipic acid, caprolactam and 1,4-butanediamine. The concepts of their synthesis from natural derivatives were briefly described below.

\section{1-Aminoundecanoic acid}

11-Aminoundecanoic acid is obtained through the pyrolysis of castor oil at $450-600{ }^{\circ} \mathrm{C} / 1 \mathrm{~atm}$, in the absence of air and in the presence of water vapor. Instead of castor oil, the transesterification product of ricinoleic acid, metyl ricinoleate, can be used as a starting material [10, 17-19]. After that step, methyl undecenoate and

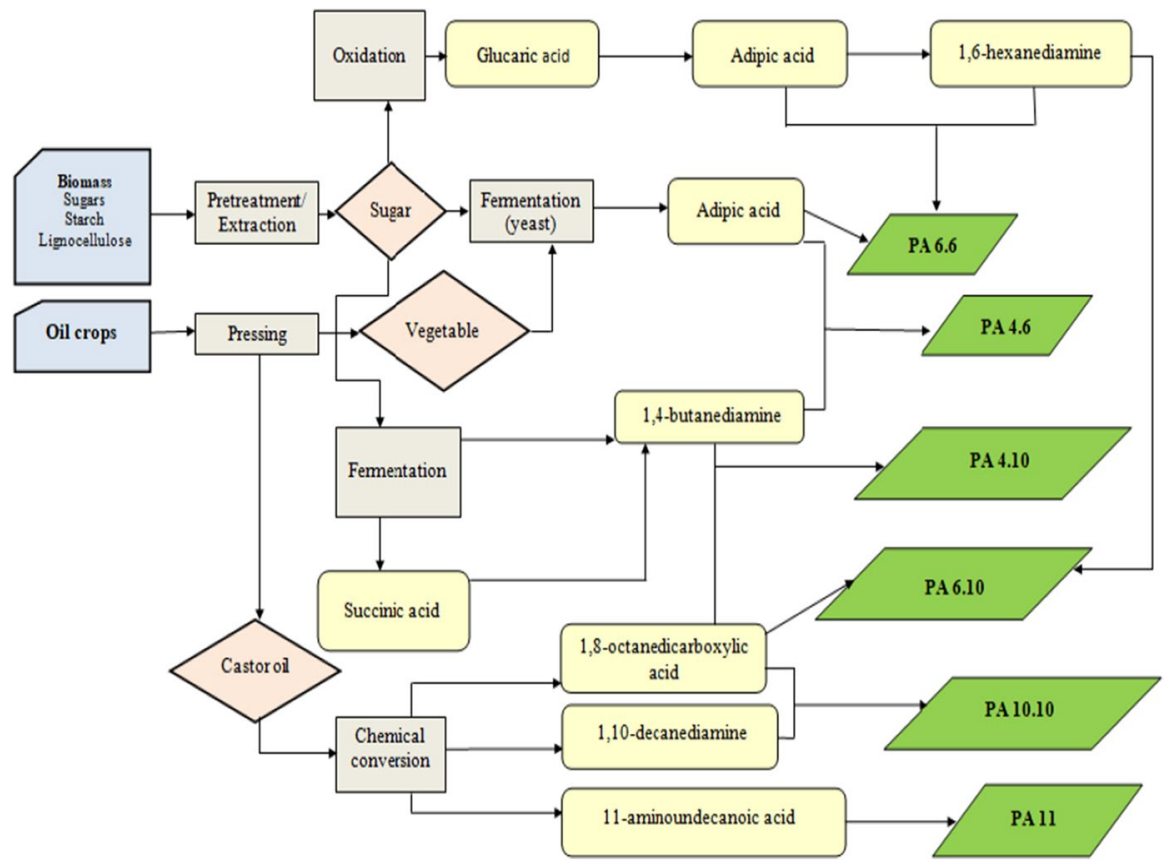

Fig. 1 Biopolyamides formation processes. Adapted with permission from Ref. [16] 
heptaldehyde are obtained. The first of mentioned products is then hydrolyzed to obtain undecenoic acid, which in the next step reacts with hydrogen bromide. This reaction is carried out in a nonpolar solvent to facilitate reverse addition reaction resulting in bromoundecanoic acid formation. The last step, in which solid 11-aminoundecanoic acid is obtained, is an ammonia treatment of bromoundecanoic acid [10]. To form bioPA11 from 11-aminoundecanoic acid, water solution polycondensation followed by reactant water extraction is carried out. The manufacturing of 11-aminoundecanoic acid is well-established technology and biopolyamide 11, as a commercial material produced for decades under the trade name Rilsan, is an exception among biopolyamides.

\section{Sebacic acid}

1,8-Octanedicarboxylic acid, commonly known as a sebacic acid, is a monomer used for synthesis of biopolyamides such as PA 4.10, PA 5.10, PA 6.10 and PA 10.10. Alkali treatment of castor oil is a process which leads to separation of intermediates containing 8 and 10 carbon atoms in a molecular chain. The alkali splitting is carried out using $\mathrm{NaOH}$ or $\mathrm{KOH}$ and a catalyst at elevated temperatures [17, 19, 20]. Diamond et al. reported that the treatment of ricinoleic acid methyl ester with alkali, using 2:1 molar ratio of alkali to the ester, in the temperature range between 250 and $270{ }^{\circ} \mathrm{C}$, leads to the formation of sebacic acid and 2-octanol [21]. Using lead tetroxide as a catalyst leads to higher yields of sebacic acid [19]. The synthesis of different types of polyamides using this diacid is performed via polymerization with diamines and the type of obtained polyamide depends on the number of carbon atom in diamine chain [22].

\section{Adipic acid}

On an industrial scale, adipic acid is produced currently from benzene. This process involves intermediate products-cyclohexane, cyclohexanol, and cyclohexanone. Nevertheless, there have been developed some bio-based pilot processes for this diacid production. According to Niu et al., there is a possibility of adipic acid production from glucose. The fermentation is conducted using modified Escherichia coli [23]. Additionally, there are some yeast (Candida yeast) which can be used for adipic acid production from vegetable oils and sugars [16, 24]. Another approach includes catalytic oxidation of glucose to glucaric acid, which then can be reduced to adipic acid [25]. Additionally, there are attempts to produce bio-based hexanediamine via conversion of adipic acid. Polycondensation of adipic acid and hexanediamine obtained from renewable resources leads to the production of fully bio-based PA $6.6[16,25]$.

\section{1,10-Decanediamine}

1,10-Decanediamine is a monomer which can be obtained from sebacic acid in a number of steps. At first, the sebacic acid is exposed to gaseous ammonia, so the 
diammonium sebacate is formed. The next step is a dehydration process, which leads to dinitrile octamethylene dicyanide formation. After hydrogenation in the presence of potassium hydroxide and a nickel catalyst the final product-decamethylene diamine (DMDA), is obtained [2, 10, 26]. Polycondensation of this diamine with diacids is a useful path toward biopolyamide synthesis.

\section{1,4-Butanediamine and 1,5-pentamethylenediamine}

Microbial synthesis is a promising technology for low molecular mass building blocks for polymers, including diamines. For example, bio-based butane diamine can be obtained via biochemical route by fermentation of glucose with metabolically engineered strain of Escherichia coli $[16,27]$. Diaminopentane can be produced by Carynebacterium glutamicum from xylose, a major constituent of hemicellulose [28] and from L-lysine [29]. Short chain diaminopentane when condensed with longchain bio-based sebacic acid produced polyamides with comparable mechanical strength as petrochemical PA 6 and PA 6.6 at lower specific density [30].

\section{Caprolactam}

Bio-based caprolactam can be obtained from lysine derived from glucose. The process comprises heating of L-lysine salt in a solution containing an alcohol and then deaminating of the obtained intermediate [31]. Buntara et al. described a method of caprolactam synthesis from 5-hydroxymethylfurfural obtained from glucose or fructose. The first step involves 1,6-hexanediol formation, which then is converted into caprolactone. The last step is the reaction of caprolactone with ammonia to form the desired product [32].

\section{Synthesis of biopolyamides from other bio-based monomers}

There were numerous other bio-based monomers reported that underwent polycondensation and ring-opening reactions and were useful in engineering of biopolyamide properties. The type and content of the special monomers influence the basic physical characteristics of biopolyamides, such as glass transition temperature, crystallinity, melting point, mechanical performance, low-temperature behavior, and often impart specific functional properties, e.g., adhesive or optical properties. The groups of other bio-resourced building blocks and their influence on biopolyamides properties were discussed below.

Polycondensation reactions in biopolyamides synthesis can be performed using bio-based dicarboxylic acids and diamines or bifunctional amino acids. In general, the synthesis of fully bio-based dyadic polyamides is more difficult than monadic ones, because of the difficulties in biodiamines synthesis [2].

There are some bio-based monomers from fatty acids which are useful in polycondensation reactions. They offer alternative synthesis paths for long-chain polyamides which are of industrial interest due to reduced hydrogen bond density and, as 
a result, reduced water uptake, high dimensional stability of molded parts in variable humidity conditions, lower melting point and thus easier processing. The example is brassylic acid (1,11-undecanedicarboxylic acid) derived from the crambe seed oil $[2,33]$ by ozonolysis of erucic acid, a $\mathrm{C}_{22}$ straight-chain monosaturated acid constituting $55 \%$ to $60 \%$ of the acids in the crambe oil. A biotechnological processing of palm oil leads to $\omega$-amino lauric acid, which is a monomer for polyamide 12 [34].

Another approach was presented by Kolb et al. who described a way of PA 16 preparation using long-chain monomer-methyl 16-aminohexadecanoate. This monomer was prepared by transformation of the mesylated fatty acids methyl esters (FAME), to the azide which was then reduced to obtain the building block for PA 16 [35]. Stempfle et al. synthesized long-chain polyamides via polycondensation reaction using previously prepared $\mathrm{C}_{19}$ and $\mathrm{C}_{23} \alpha, \omega$-diamines and $\alpha, \omega$-diacids, the monomers obtained from unsaturated fatty acids esters. The melting point of PA 19.23 and PA 23.23 was $156^{\circ} \mathrm{C}$ and $152{ }^{\circ} \mathrm{C}$, respectively $[2,36]$.

Additionally, there is a possibility of unsaturated polyamides synthesis through polycondensation reaction of substrates originating from natural fatty acids. Examples of such compounds are Z-octadec-9-enedioic acid [37], dimethyl(E)-icos10-enedioate obtained by self-metathesis of methyl-10-undecenoate [38] and dimethyl 1,19-nonadecanedioate [39]. Unsaturated linear aliphatic polyamides could be potentially used as thermoreactive sealants, barrier and adhesive films or hightemperature rigid materials. They have also reactive species susceptible for further chemical derivatization.

Unsaturated monomers were also used for the synthesis of branched aliphatic polyamides [40]. For this purpose, unsaturated fatty acid methyl esters were subjected to hydrobromination, then the obtained bromides were further converted into azides, which were subsequently reduced to amines. The obtained aminoacids had long alkyl chains in the proximity of amine functionality that strongly influenced the intermolecular interactions of resulting biopolyamides. The melting temperatures of branched bioPA were found too low $\left(40\right.$ and $89{ }^{\circ} \mathrm{C}$ ) for practical application of homopolymers, but branched monomers could be useful for the synthesis of copolymers with tailored thermal properties. Another strategy for derivatization of unsaturated fatty acid methyl esters was direct synthesis of keto-fatty acid esters by Wacker oxidations employing oxygen as a sole re-oxidant and amine functionalization of the thus obtained keto-fatty acid esters by reductive amination [41]. In another work, unsaturated bond of fatty acid-derived methyl 10-undecenoate, methyl oleate, and methyl erucate was utilized in the thiol-ene addition reaction of cysteamine hydrochloride to obtain amine functional branched monomers [42]. Monomers were further used to obtain homo and copolymers with adjustable thermal and solubility properties.

Introduction of cyclic aliphatic structures into the PA backbone also interferes the crystalline phase formation and molecular cohesion of polymer leading to a more flexible material. For example, cycloaddition of two unsaturated fatty acids were applied to obtain monomers with cyclic moieties [43, 44].

Another group of raw materials for bio-based polymers are carbohydrates, with the cellulose obtained from non-food resources as a main potential feedstock for the industrial scale production. A big advantage of carbohydrates is that they offer 
a wide range of functionalities that can be implemented into the biopolymers. The examples of renewable monomers from carbohydrates are furan-2,5-dicarboxylic acid [45], carbohydrates as sources of tartaric acid [46], as well as rosin acids [2].

Furan-2,5-dicarboxylic acid (FDCA)-based furanic-aliphatic polyamides were recognized as sustainable alternatives to polyphthalamides used as high-performance heat resistant materials [47, 48]. Bio-resourced counterparts showed comparable thermal properties in terms of glass transition and melting behavior but lower melting temperatures (c.a. $160{ }^{\circ} \mathrm{C}$ ) that allows energy savings during processing. Moreover, Jiang et al. demonstrated effectiveness of enzymatic polymerization by Novozym 435 with achievable high molecular mass at relatively low temperature $\left(90{ }^{\circ} \mathrm{C}\right)$, as compared to conventional polycondensation techniques. They found that further lowering of polycondensation temperature is limited by the effectiveness of water and methanol (by-product) removal, the decreased solubility of FDCAbased polymers, and the restricted chain mobility of the biopolyamide below its $\mathrm{T}_{\mathrm{g}}$. Structural analysis showed further necessity for the process optimization in terms of polymer dispersity. Thus, application of lipase can be a solution to a challenging problem of FDCA decarboxylation and extensive N-methylation of polyamides observed in the course of conventional polycondensation of this bio-based monomer at elevated temperatures.

There is also a protocol for biopolyamides synthesis using bio-monomer-itaconic acid, produced by the fermentation of Aspergillus terreus. Bio-derived itaconic acid was also used in polycondensation reactions with aromatic diamines by Ali et al. to produce degradable biopolyamies [49-51]. Another recently raised building block for sustainable polymers is succinic acid derived from glucose. The present market for succinic acid is rather small but, interestingly, the production of bio-based succinic acid is much cheaper than its petrochemical counterpart and thus experiences fast growth [8]. Polyamides obtained from succinic acid, such as PA 24, PA 44 and PA 46, show high thermal resistance and mechanical strength [52-54].

Monadic polyamides can be produced via ring-opening polymerization of lactams. Apart from the bio-based $\varepsilon$-caprolactam, there are some lactam derivatives which can be useful in ring-opening polymerization reactions. Winkler et al. [55] prepared a novel modified $\varepsilon$-caprolactone starting from 1,4-cyclohexadiene (CHD) derived from polyunsaturated fatty acid methyl esters. CHD was oxidized to form cyclohex-2-en-1-one, which was subjected to the Michael addition reaction with thiols. The product was then oxidized via Baeyer-Villiger reaction. Then, after oxime formation and Beckmann rearrangement, lactam monomer designed for the synthesis of polyamides with side groups, is formed [2, 55].

The ring-opening polymerization was used by Winnacker et al. [56] to synthesize optically active polyamides using $\varepsilon$-lactams from terpene $\beta$-pinene-Fig. 2.

Most of the desired properties of biopolyamides such as biodegradability, water solubility, specific thermal behavior, mechanical strength and ductility are related to crystallinity. Thus, crystallinity control is one of the major tasks in biopolyamide engineering. For instance, recently van Velthoven et al. [57] proposed a new biopolyamide that contained moieties of isoidide-based diamine and dimerized fatty acid to obtain rigid but amorphous biopolymer. The chemical components were rationally selected to provide the planar structure of the monomer, enhancing the rigidity 


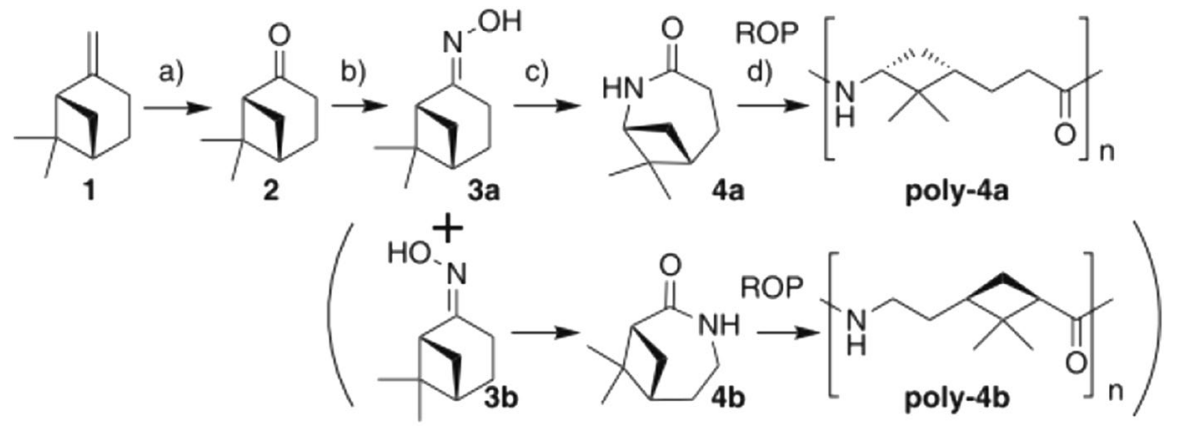

Fig. 2 Synthesis of polyamide poly-4 from $\beta$-pinene; a $\mathrm{KMnO}_{4}, \mathrm{Al}_{2} \mathrm{O}_{3}, \mathrm{H}_{2} \mathrm{O} / \mathrm{CH}_{2} \mathrm{Cl}_{2}$. b $\mathrm{NH}_{4} \mathrm{OH} \cdot \mathrm{HCl}$, $\mathrm{NaHCO}_{3}, \mathrm{MeOH} / \mathrm{H}_{2} \mathrm{O}$. c Polyphosphoric acid. d ROP=ring-opening polymerization. Reproduced with permission from Ref. [56]

of the polymer backbone for increased glass transition temperature, as well as steric hinderance combined with the introduction of the odd-even effect that hampered the regular packing of polymer chains into the crystal structure. Numerous other research works were focussed on the developed crystal structures, crystallization kinetic and temperatures of phase transitions of biopolyamides [58-60]. Though, further investigation on the structure-properties relationship of new synthetized biopolymers and its composites is still needed for better understanding of fundamental aspects and validation of future applications.

Using bio-based polyamides allows synthesis of high-performance, environmentally friendly materials. However, because of a decrease in intermolecular interactions with an increasing length of the alkyl spacer, long-chain biopolyamides exhibit worse properties, e.g., lower density, strength or stiffness, than polyamides with shorter hydrocarbon chains (e.g, PA 6) [9]. On the other hand, lesser amide groups density imparts lower water uptake and higher dimensional stability in the environment with varying humidity. Examples of specific biopolyamides' properties in relation to the monomer type are collected in Table 1 . The physical properties of polyamides, such as glass transition and melting temperature, mechanical strength and water absorption, can be adjusted by copolymerization of monomers with different chain length and structure $[33,61]$.

\section{Biopolyamide composites}

The development of new biopolyamide materials is observed both in the area of chemical synthesis, as well as further physical modification. The chemical and physical modifications reflect the specific market demands for biopolyamides as an engineering material, where mechanical performance combined with functional properties is of major interest. With this respect, biopolyamide composites emerge as an attractive final materials dedicated to the machine, automotive, building, electrical and electronics, and consumer goods industries, etc. 


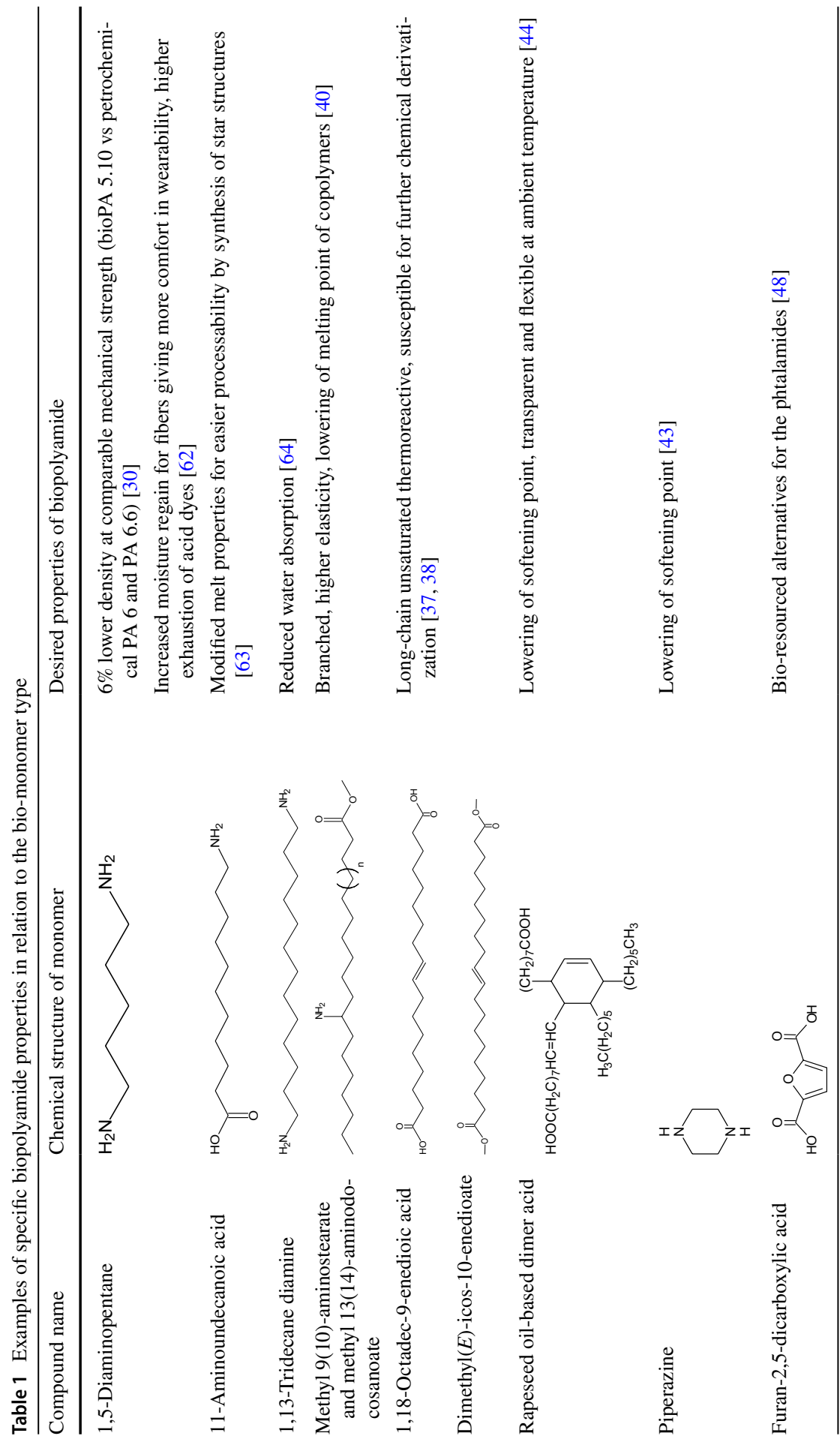




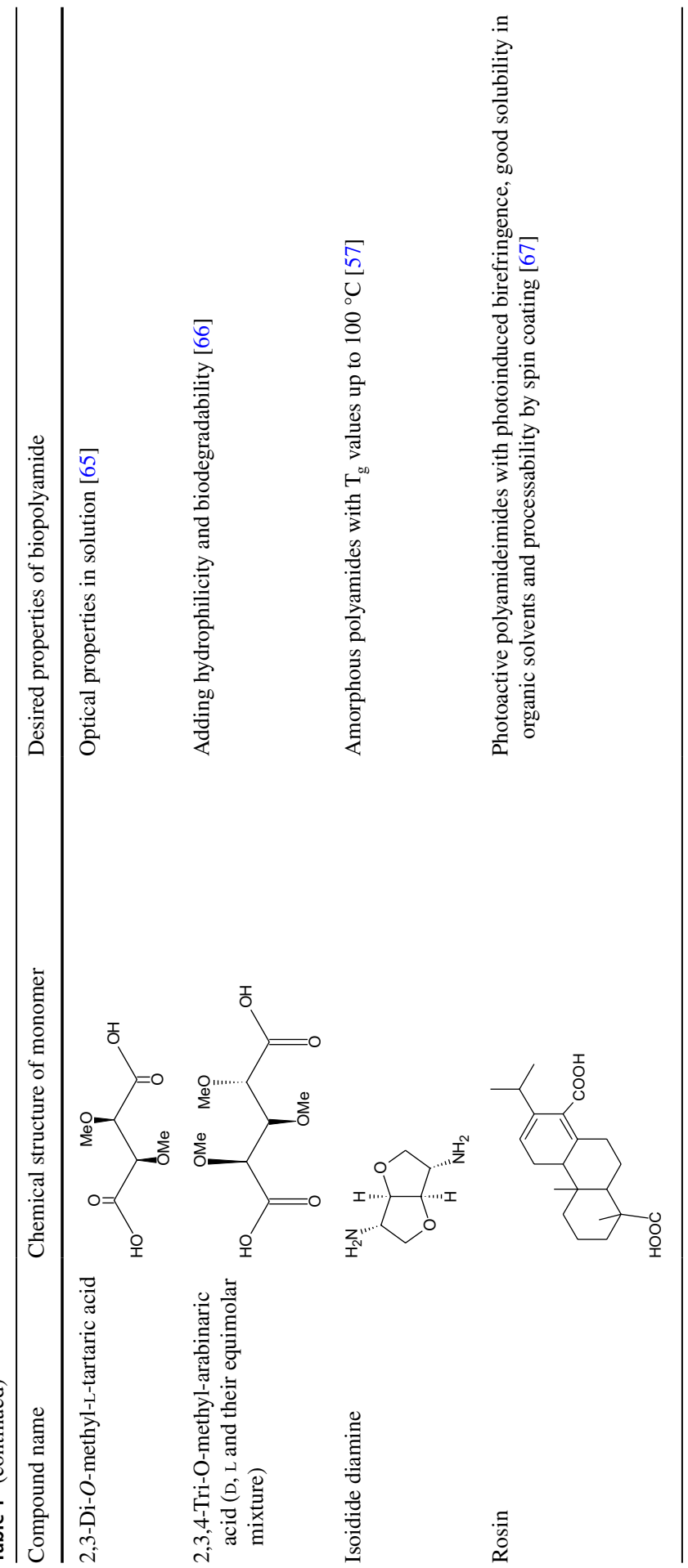




\section{Bio-based polyamides reinforced by natural fibers}

Using natural fibers as fillers in bio-based polymers gives an opportunity to obtain fully green, sustainable materials. Besides their renewable nature, natural fibers offer a wide range of valuable properties such as low density, low cost, higher strength per unit mass in comparison with inorganic fillers [68]. Moreover, these fibers are nontoxic and non-abrasive to the equipment used for composites preparation. However, the main difficulty arises from their polar and hydrophilic nature, which makes it difficult to obtain a good dispersion of fibers in hydrophobic polymer matrices. Another challenge of making such composites is that the processing temperature of some polyamides is higher than a degradation temperature of natural fillers [69].

\section{Properties of natural fibers}

Generally, vegetable natural fibers can be divided into three groups: seed fibers (e.g., cotton), bast fibers (e.g., jute) and leaf fibers (e.g., sisal) [70]. They all have an elongated shape with diameters in the range of 15-30 $\mu \mathrm{m}$ and lengths in the range of 1-50 mm, but there are high fluctuations in both dimensions. As short fibers are considered the ones that have lengths up to $5 \mathrm{~mm}$, and as long fibers - those with lengths up to $50 \mathrm{~mm}$. Application of short fibers results in composite materials with rather isotropic properties, while the long ones lead to materials with anisotropic properties, imposed by specific orientation of fibers [71].

The chemical composition of natural fibers is influenced not only by the plant type but also by the climatic conditions, plant's age and processing conditions. The main components of natural fibers are cellulose, hemicellulose, and lignin. Other ingredients are extractives, starch, inorganics, and protein [72]. Generally, in plant fibers cellulose content increases after processing as the result of the non-cellulose components removal. Due to the high crystallinity degree of cellulose, there is a correlation between cellulose content and stiffness and strength of fibers [71, 73]. Mechanical properties depend also on the aspect ratio of fibers and openness of the fibrous material [72].

Investigation on the thermal decomposition of ten types of natural fibers (woodmaple, wood-pine, bagasse, bamboo, cotton stalk, hemp, jute, kenaf, rice husk and rice straw), provided by Yao et al. [68], showed that for most of them thermal decomposition occurs in the temperature range between 215 and $310{ }^{\circ} \mathrm{C}$. The degradation process runs in two stages - the first one is associated with hemicellulose degradation, and the second one with degradation of lignin [70]. Results of the thermogravimetric analysis indicate that some problems may occur when natural fibers are processed at elevated temperatures to obtain composites with thermoplastic polymers. In order to improve the thermal stability of natural fibers and, moreover, their compatibility with hydrophobic polymer matrices, surface modification has to be performed by a physical or chemical method. Physical methods include corona, gamma and cold plasma treatment, whereby chemical methods include the use of coupling agents, such as silanes, impregnation with compounds compatible with the polymer matrix, mercerization (alkali treatment) and chemical coupling through "linkers" which are able to form chemical bonds with both the fiber and the polymer 
matrix in composite material $[69,72,74]$. Preparation of polymeric composites reinforced by natural fibers requires also careful drying of the filler, as fibers are characterized by high water absorption. The presence of water on the surface of processed components results in voids caused by water evaporation and separation of the surfaces of fibers and the matrix. Consequently, mechanical properties of polymeric materials decrease [70, 72]. Water content must be kept especially low when natural fibers are processed with polymers susceptible for hydrolysis at elevated temperatures, such as polyamides. Despite the difficulties arising from relatively low thermal stability and high water absorption, polymer composites with natural fibers are a vast group of composite materials that have been studied for the last three decades.

\section{Properties of biopolyamide composites with natural fibers}

Researches considered different approaches to develop biopolyamide/natural fibers-composites with improved properties in comparison with unmodified materials. One of the paths includes manufacturing of the composite materials in which matrix is a blend of bio-based polyamide and some polyolefins, e.g., polypropylene. Another solution is addition of the mixture of natural and synthetic fibers into the bioPAs. Moreover, some researchers used unmodified natural fibers as the reinforcement for the polyamides, while others conducted modification of fibers surfaces before dispersing them into the polymers. In this section, the influence of natural fibers on the properties of different biopolyamides will be reviewed.

\section{The morphology and structure of biopolyamides reinforced by natural fibers}

Biopolyamide 11 and its blends with polypropylene reinforced by wood fibers, carbon fibers, and the mixture of both fillers have been investigated by Armioun et al. [75]. The morphology studies of the fractured surfaces of composite materials showed that those which contained only wood fibers had better adhesion between the filler and the matrix than composites containing the mixture of natural and synthetic fibers, though the latter had lower values of the impact strength. The main fracture mechanism in case of composites containing only wood fibers was fiber breakage, while in hybrid composites there were also fiber pullouts-Fig. 3. The same fracture behavior was observed for blends of biopolyamide and polypropylene [75, 76].

Investigations done by Kuciel et al. on composites made of Hiprolon 211 and flax fibers proved a good fiber-matrix adhesion, which was confirmed by the improvement of mechanical properties. SEM images confirmed that biopolyamide composites can be processed with no thermal degradation of the fibers, as there were no visible signs of thermal damage and deformations of the fibers [9].

Another approach was reported by Nishitani et al. Investigations carried out on biopolyamide 10.10 reinforced by hemp fibers modified with sodium hydroxide solution, sodium chlorite solution $\left(\mathrm{NaClO}_{2}\right)$ and surface treated using ureidosilane coupling agent, showed that fibers after treatment with $\mathrm{NaClO}_{2}$ and silane coupling agent had better adhesion to the matrix than those which were treated only with $\mathrm{NaOH}[77]$. 

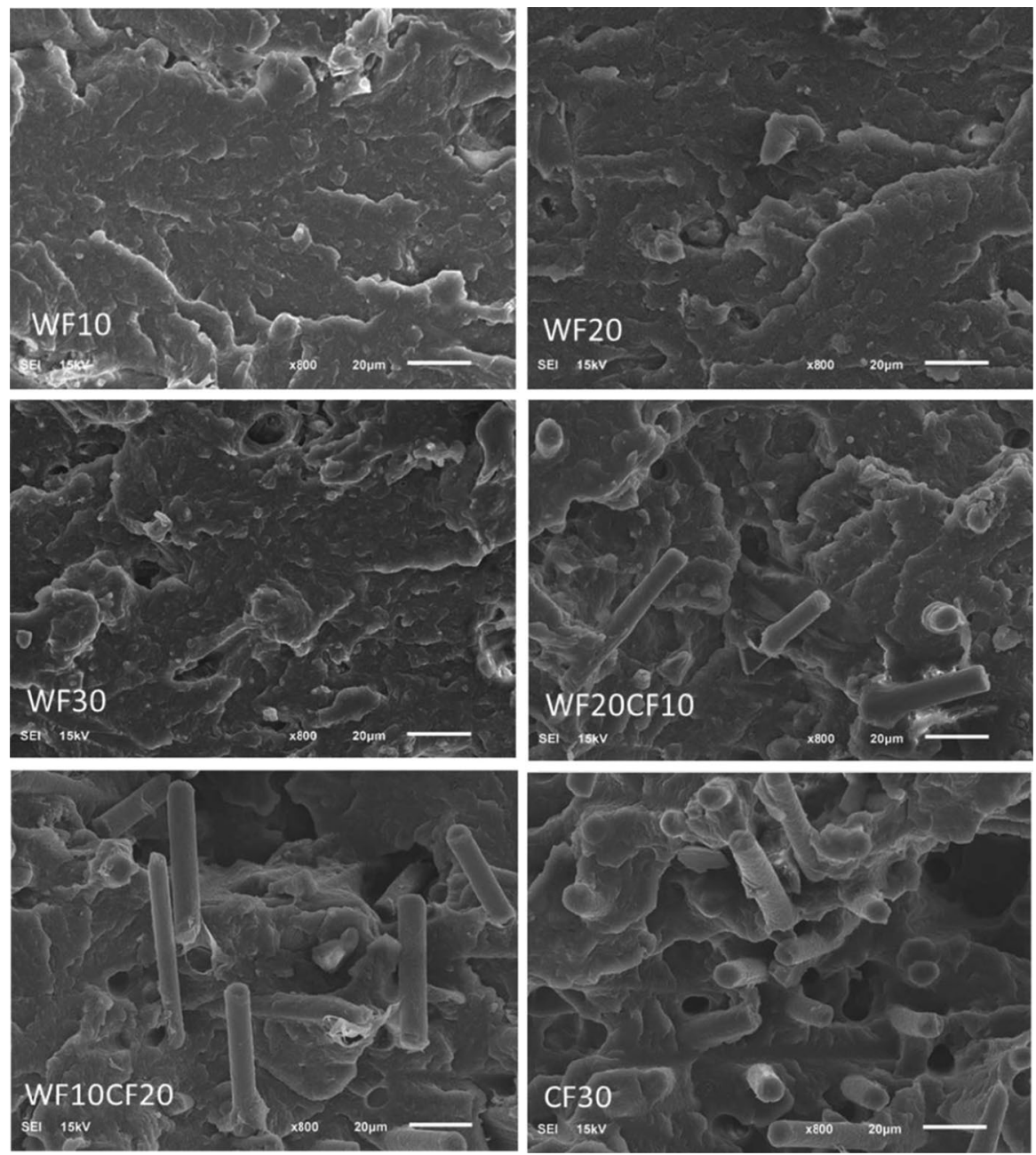

Fig. 3 SEM photographs of bioPA 11 composites containing wood fibers (WF) and carbon fibers (CF). Reproduced with permission from Ref. [75]

Besides using the natural fibers, some researchers reported the use of processed cellulose fibers as the reinforcement for biopolyamides. The influence of such fibers on the mechanical and thermal properties of composites was investigated but also the length of the fibers after processing was measured. The processing methods used for composites preparation included extrusion and injection molding.

Feldmann and Bledzki have investigated the composites of polyamide 6.10 and 10.10 with 15 and $30 \mathrm{wt} \%$ of cellulosic fibers. The SEM pictures of those materials showed that there was low compatibility of cellulosic fibers and hydrophobic 6.10 polyamide matrix which resulted in fibers pullouts after material breakage and the presence of the gaps between the filler and the matrix. Authors prepared also the 
composite containing $15 \mathrm{wt} \%$ of glass fibers which exhibited better adhesion with polyamide [78].

On the other hand, partial compatibility of cellulose fibers and dimer fatty acidbased polyamide was showed by Hablot et al. for the composite containing $20 \mathrm{wt} \%$ of cellulosic fibers. Though some holes after fibers pullouts were observed by the authors, SEM investigations indicated a good wetting of the fibers by the polyamide as the majority of fibers were cut at the level of the fracture surface [79].

Moreover, the influence of processing parameters on the biocomposite properties was studied by Leszczynska et al. Bio-based polyamide 4.10 was modified with acetylated microfibrillated cellulose (MFC-Ac). Authors investigated the influence of screw speed during extrusion on the dispersion degree of the fibers and resulting dynamic mechanical properties. SEM analysis showed that using screw speed of $50 \mathrm{rpm}$ was not enough to disperse the filler evenly. Higher values of screw speed (100 and $150 \mathrm{rpm}$ ) resulted in better dispersion, although at the highest speed the bubbles and defects were formed due to local overheating during processing [80]. Figure 4 shows SEM microphotographs of composites obtained at different screw speeds containing $3 \mathrm{wt} \%$ of the acetylated microfibrillated cellulose.

Morphology studies of composite materials prepared with different natural fillers showed that applying proper surface treatment leads to materials with good adhesion of the filler to the matrix, and thus materials in which efficient stress transfer from matrix to the fiber will be achieved.

\section{Mechanical properties of biopolyamides reinforced by natural fibers}

The main role of natural fibers in polymer composites is to improve their mechanical performance. Investigations on mechanical properties of biopolyamide 11 reinforced by wood fibers showed that with the increase in fibers content, the tensile strength, tensile modulus, flexural strength and flexural modulus increased. In the case of biopolyamide 11 containing $30 \mathrm{wt} \%$ of wood fibers, these parameters were 43.3 MPa, 1.78 GPa, 69.9 MPa and 1.80 GPa, while for neat PA $1135.4 \mathrm{MPa}, 1.04$ $\mathrm{GPa}, 53.5 \mathrm{MPa}$ and 1.10 GPa, respectively [75]. The same dependence of the tensile strength and fiber content was observed for polyamide 11 with stone groundwood fibers. However, after addition of $60 \mathrm{wt} \%$ of fibers the tensile strength decreased $[81,82]$. Improvement of tensile properties in composites is related to the ability of transferring the stress between the polymer and the fiber and indicates a good interfacial adhesion between the filler and the matrix.

Studies of shear properties of biopolyamide 11 and flax fiber composites provided by Le Duigou et al. [83] proved that there is a linear (increasing) dependence between the shear stiffness and the fiber content, whereas there was no strong influence of the natural fibers content on the shear strength of the biopolyamide. Generally, incorporation of natural fibers into bio-based polyamides improved mechanical properties such as tensile and flexural strength and modulus. These observations were confirmed in other studies on biocomposites containing flax and beech fibers [9, 74]. Unfortunately, the impact strength decreases after addition of the filler, which is the weak point of composites containing natural fibers. Both notched and unnotched impact strengths have significantly lower values for composite materials 

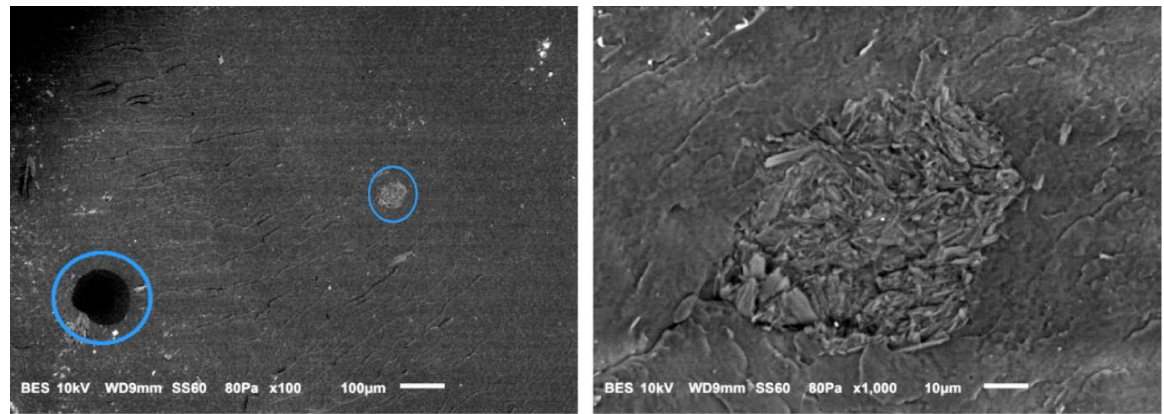

PA/MFC-Ac-3\%_50
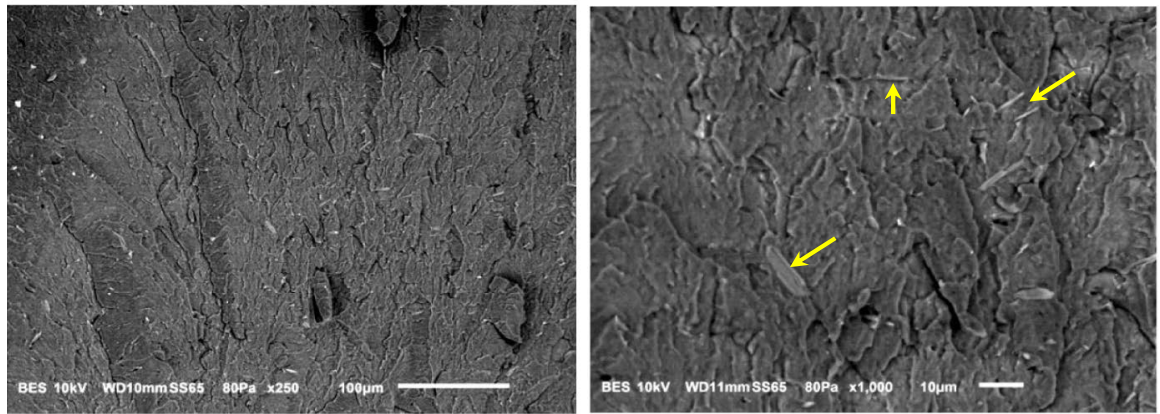

PA/MFC-Ac-3\%_100
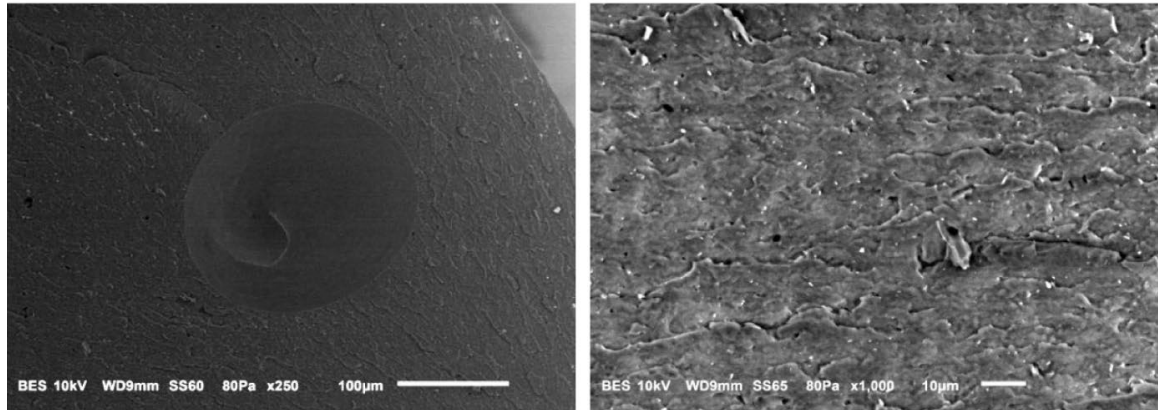

PA/MFC-Ac-3\%_150

Fig. 4 SEM photographs of PA 4.10/MFC-Ac composites prepared at different screw speeds. a $50 \mathrm{rpm}, \mathbf{b}$ $100 \mathrm{rpm}, \mathbf{c} 150 \mathrm{rpm}$. Reproduced with permission from Ref. [80]

than for the neat polyamide 11. Investigation of mechanical performance of dimer fatty acid-based polyamide composites showed that the Yung's modulus and the yield stress of the materials increased with increasing content of cellulose fibers which indicated good dispersion of the fibers and sufficient interactions between the filler and the matrix [79, 84].

Cellulose fibers efficiently improve mechanical performance of polyamides, and thus, such materials are another alternative for obtaining environmentally friendly 
materials for high-performance applications. However, some reports showed superior mechanical behavior of biopolyamide reinforced by synthetic fibers or mixed natural/synthetic reinforcement as compared with natural fillers. Although the composites comprising a mixture of natural and synthetic fibers showed inferior properties as compared to composites containing solely carbon fibers, they were still interesting from the viewpoint of the cost/weight ratio [74-76]. In hybrid composites, with the increasing content of the carbon fiber, the tensile and flexural strength of the composites was enhanced. The same trend was observed for tensile and flexural modulus. Such results arise from the higher strength and modulus of carbon fibers in comparison with the natural ones. Tensile modulus for the hybrid composite containing $10 \%$ of wood fibers and $20 \%$ of carbon fiber was improved by $168 \%$, in comparison with composite with only wood fibers, and the flexural modulus was enhanced by $142 \%$. It is worth to mention that incorporation of synthetic fibers also improves notched and unnotched impact strength of the composites containing natural fibers. The same results were obtained for composites where the matrix was made of biopolyamide and polypropylene blend $[75,76]$.

The influence of compounding process conditions on the mechanical properties of composites made of PA 6.10 and PA 10.10 was investigated by Feldmann and Bledzki. Single-step and two-step compounding techniques were applied, and it was found that tensile and impact strength have higher values in the one-step process due to the lower thermal and mechanical stresses imparted on the material than in the two-step approach. Further investigations of mechanical properties on these biopolyamides containing 15 and $30 \mathrm{wt} \%$ of cellulosic fibers were compared with composites containing $30 \mathrm{wt} \%$ of glass fibers. Composites with $30 \mathrm{wt} \%$ of cellulosic fibers had two times higher values of tensile strength (120 MPa) than neat polyamide, however, still lower than that of composites containing glass fibers. On the other hand, biopolyamide reinforced with natural fibers was superior to composite with glass fibers in terms of elongation at break and notched impact strength [78].

The mechanical properties of biopolyamide 10.10 containing chopped cellulose fibers were also investigated by Nikiforov et al, who compared the properties of such materials with the composites of PA 10.10 containing carbon and glass fibers. Results showed that the highest values of tensile elastic modulus were obtained for composites containing carbon fibers $(6.34 \mathrm{GPa}$ for 6 vol\% of fibers, and $10.15 \mathrm{GPa}$ for $12 \mathrm{vol} \%$ ). At the same volumetric filling, the composites containing cellulose fibers had values of elastic modulus 2.27 and $2.74 \mathrm{GPa}$, respectively [85].

\section{Thermal and thermomechanical properties of biopolyamide composites}

Understanding of thermal properties of composites reinforced by natural fibers is an important issue because of the relatively low thermal stability of these fibers in comparison with polymer matrix. Nishitani et al. investigated thermal properties of biopolyamide 10.10 reinforced by hemp fibers treated with various chemicals, e.g., $\mathrm{NaOH}, \mathrm{NaClO}_{2}, 3$-(2-aminoethylamino) propyltrimethoxy silane. The results of the thermogravimetric analysis (TGA) showed that the thermal stability of neat polyamide is higher than composites in the whole temperature range. Additionally, degradation of unmodified polyamide was a single-stage process, while for the composite 
materials there were two stages of thermal decomposition. Authors explain that the first stage, occurring between 80 and $200{ }^{\circ} \mathrm{C}$, is related to the degradation of hemicellulose and lignin, as well as to the absorbed water evaporation. The second stage, at $300{ }^{\circ} \mathrm{C}$, is probably the degradation process of cellulose and polymeric matrix. Moreover, TG data revealed that in the case of composites with modified hemp fibers, thermal stability of composites containing fibers treated with the combination of sodium hydroxide and amino silane is higher than those in which fibers were treated with only one of the chemicals, and also higher than those containing raw fibers [77].

The investigations carried out on biopolyamide 11 reinforced by wood fibers showed some similar effects as those discussed above, namely the thermal decomposition of composites proceeded in two stages. The first stage, which started at $200{ }^{\circ} \mathrm{C}$, was associated with the degradation of fibers, while the second one at $350{ }^{\circ} \mathrm{C}$ with the polyamide degradation. This indicated that thermal stability of composites containing wood fibers is lower than neat biopolyamide 11 . Nonetheless, authors noticed that with an increase in the fiber content, the onset temperature of the second decomposition stage slightly got higher as a result of possibly good interaction of fibers and polyamide. It was also observed that the rate of the thermal decomposition was decreasing after the addition of synthetic fibers, and thus, enhancing the thermal stability of composites. [75].

Some studies of the thermal behavior of biopolyamides composites with natural fibers indicated that using raw fibers would result in deterioration of materials thermal stability. The perspective for resolving this problem is a prior modification of the fibers before composites processing or manufacturing of biocomposites containing natural and synthetic additives. Chemical modifications of natural fibers presented in the literature include alkali, acetyl, silane, benzyl, acryl, permanganate, peroxide, isocyanate, titanate, zirconate and acrylonitrile treatments and use of maleated anhydride grafted coupling agent. Additionally, environmentally friendly enzyme treatment has been gaining more and more interest recently [86, 87]. Except improvement of fibers thermal stability, chemical modification enhanced compatibility between fibers and matrix, and thus positively affected their mechanical performance.

Thermal properties of different biopolyamides and composites of bioPA 4.10 containing 1, 3, $5 \mathrm{wt} \%$ of cellulosic fibers were further investigated by Leszczynska et al. [80] and Pagacz et al. [89]. The approach employed by the authors included modification of cellulose fibers before composites preparation. Surface acetylation of microfibrillated cellulose (MFC) by acetic anhydride resulted in substantial thermal stability enhancement due to the non-cellulose components removal and partial esterification of hydroxyl groups; the onset temperature of degradation was reported to be $277^{\circ} \mathrm{C}$ for the raw fibers, while for the fibers after modification this temperature was above $316^{\circ} \mathrm{C}$ [80]. Melting temperatures of composites determined by DSC method were slightly decreased as the cellulose content increased, while the crystallization temperatures were shifted to the higher values after addition of the filler due to heterogeneous nucleation of polyamide crystallization. Dynamic mechanical analysis showed that the highest value of storage modulus was obtained for the composite containing $5 \mathrm{wt} \%$ of cellulosic filler extruded at screw speed of 
$150 \mathrm{rpm}$, although at this screw speed material's deterioration may occur due to overheating effects [80, 88, 89]. Moreover, Leszczynska et al. investigated the effect of surface modification of microfibrillated cellulose by acid chlorides on the structural and thermomechanical properties of biopolyamide 4.10 nanocomposites produced by melt blending. Dynamic mechanical analysis (DMA) showed that there is a dependence on composite performance on the length of alkyl chain attached to the surface of cellulose fibers. Modification of the fibers with acid chlorides with longer alkyl chains resulted in decrease in storage modulus in comparison with the shorter ones (Fig. 5) [90].

Also some studies of biopolyamide composites containing unmodified cellulosic fibers are presented in the literature. Investigations provided on dimer fatty acidbased polyamides showed that the introduction of cellulosic fibers resulted in a significant increase in glass transition temperature, from -10 to $-3{ }^{\circ} \mathrm{C}$ for pure polyamide and composite containing $20 \mathrm{wt} \%$ of the fibers, respectively. Increasing of the glass transition temperature with increasing cellulose fiber content may be explained by the formation of interactions between polyamide carbonyl and cellulose hydroxyl groups which reduced the mobility of polymer chains. It is worth to mention that the reduction of polymer chains mobility also induced the decrease in the crystallization temperature [91]. Results obtained from dynamical mechanical thermal analysis showed that the addition of cellulosic fibers into dimer fatty acid biopolyamides results in increase in storage modulus with increasing cellulose content $[79,84,91]$.

\section{Other properties of biopolyamides reinforced by natural fibers}

Other properties which are important for the efficient processing and further applications of composite materials based on biopolyamides and natural fibers are melt flow index (MFI), heat deflection temperature, and water uptake. As incorporation of fibers causes a decrease in the mobility of macromolecules, the values of MFI are lower for composite materials in comparison with unmodified polyamide and decrease with the increasing fiber content. The temperature at which polymer deforms under a particular load is the heat deflection temperature (HDT). According to Armioun et al. HDT for biopolyamide 11 was $44^{\circ} \mathrm{C}$ and no significant improvement of this parameter was observed after incorporation of natural fibers. High water absorption is one of the disadvantages of natural fibers because the presence of water during composites processing can result in dimensional instability, surface defects, and decrease in mechanical properties. In composite materials based on biopolyamide 11 and wood fibers, the water uptake increased with an increasing fiber content. The highest value of water absorption was observed for composite containing the highest addition of wood fibers (30 wt\%), for which this parameter increased by $70 \%$ in comparison with neat PA11 $[75,76]$.

Studies of different biopolyamides reinforced with natural fibers indicated that such green materials can be manufactured and used as an alternative for some petrochemical plastics. The main approach included manufacturing of hybrid composites containing natural and synthetic fibers to achieve a compromise between the mechanical and thermal performance and a cost, as well as density and environmental aspects. Beside the most widely described composites of bioPAs with 

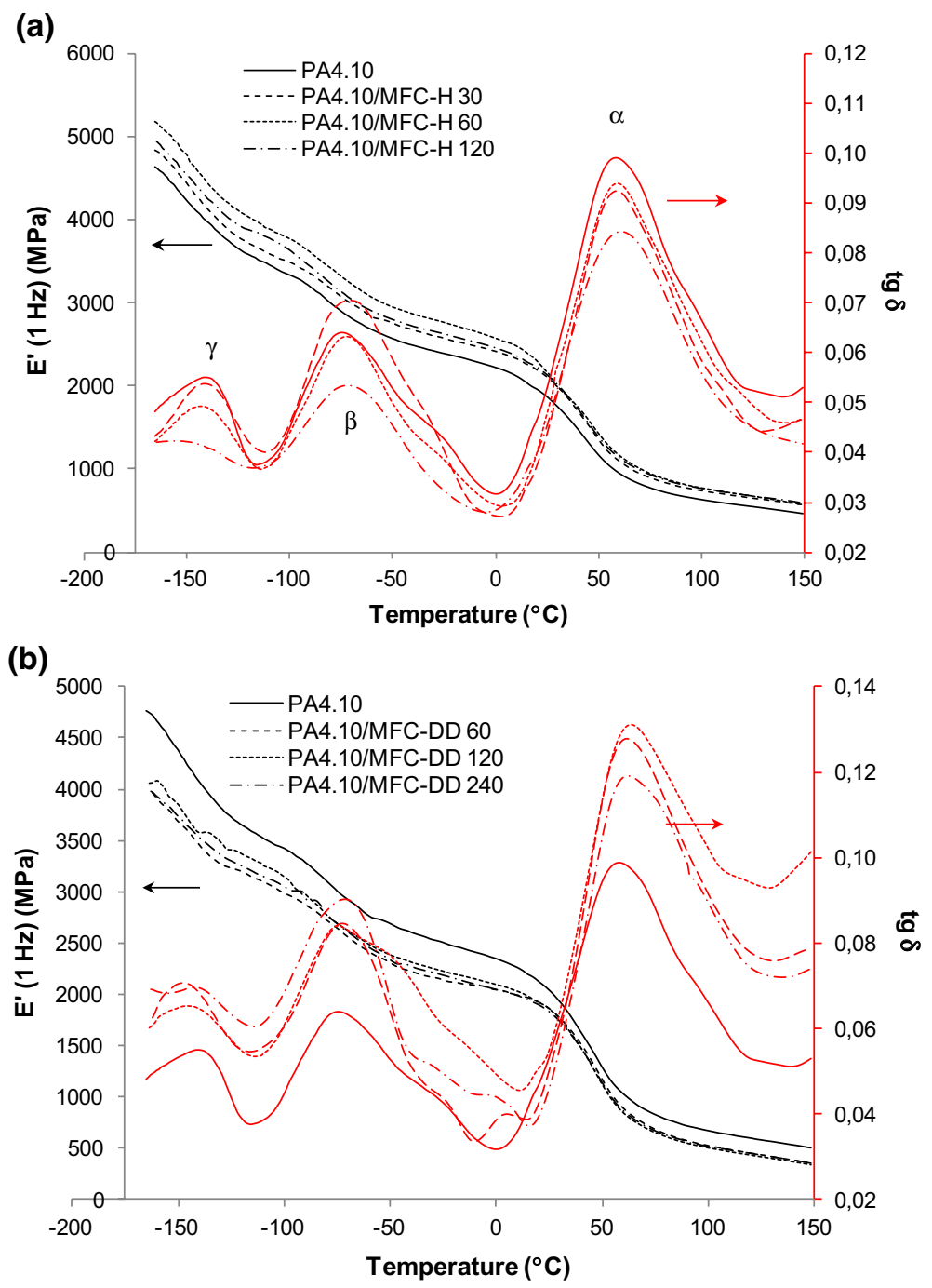

Fig. 5 Bending storage modulus and $\operatorname{tg} \delta$ for PA 4.10 composites containing $3 \mathrm{wt} \%$ of MFC modified with hexanoyl chloride (a) and dodecanoyl chloride (b) obtained after different times of reaction. Reproduced with permission from Ref. [90]

natural fibers, also biopolyamides composites containing processed cellulose fibers are described in the literature as a promising material. 


\section{Biopolyamides reinforced by other additives}

Although particular attention is paid to the bio-based polyamide composites with natural or cellulose fibers or mixtures of those natural fillers with glass or carbon fibers, there are also reports on biopolyamides composites reinforced by carbon fibers, boron nitride microparticles, composites containing nutshell powder modified with nanosilver particles or rice husk and nanoclay [92-95]. For instance, Hajibeygi and Omidi-Ghallemohamadi have synthesized a semi-aromatic bio-based polyamide via triphenyl phosphite-activated polycondensation reaction and prepared $\mathrm{Mg}-\mathrm{Al}$ layered double hydroxide containing composites with enhanced thermal stability [96]. There are also some investigations of thermal stability and flammability of polyamide 11 composites with lignins or nanoboehmite, which causes the increase in thermal stability and reduction of heat release and mass loss rate [97, 98]. Such materials offer novel applications for bio-based polyamides.

\section{Carbon fibers}

Mechanical properties of biopolyamide 10.10 reinforced by carbon fibers were described by Kuciel et al. Authors investigated two different types of polyamide 10.10. The filler contents were 10 and $30 \mathrm{wt} \%$ and 20 and $40 \mathrm{wt} \%$, respectively. Mechanical performance of all composite materials was better than those of unmodified polyamides. Values of such parameters as tensile strength and modulus or flexural strength and modulus increased with an increasing fiber content, e.g., for neat biopolyamide those parameters were 51.4 MPa, 2030 MPa, 62.5 MPa and $1676 \mathrm{MPa}$, respectively, while for its composite containing $40 \mathrm{wt} \%$ of carbon fibers they took values of 184.9 $\mathrm{MPa}, 23,645 \mathrm{MPa}, 283.0 \mathrm{MPa}, 19,830 \mathrm{MPa}$, respectively [92]. The substantial improvement of mechanical performance was also observed for biopolyamide 11 reinforced by carbon fibers [75, 92]. Another advantage from carbon fibers incorporation into bio-based polyamide matrix is the reduction of water absorption [76, 92].

\section{Boron Nitride}

In order to produce environmentally friendly materials useful in electronic packaging applications, Mosanenzadeh et al. investigated the properties of bio-based polyamide 30 and 90 that were melt blended with boron nitride microparticles and then compression molded-Fig. 6.

The choice of this filler comes from its high thermal conductivity and electrical resistivity. Authors analyzed such properties as thermal conductivity, thermal expansion and electrical insulation, as well as mechanical and rheological properties of composites. Results showed that the effective thermal conductivity of polyamides and boron nitride composites increases with an increasing filler amount. Higher values of this parameter were obtained for the samples in which PA 30 was used as a matrix. Moreover, because of the insulative properties of both components, the 


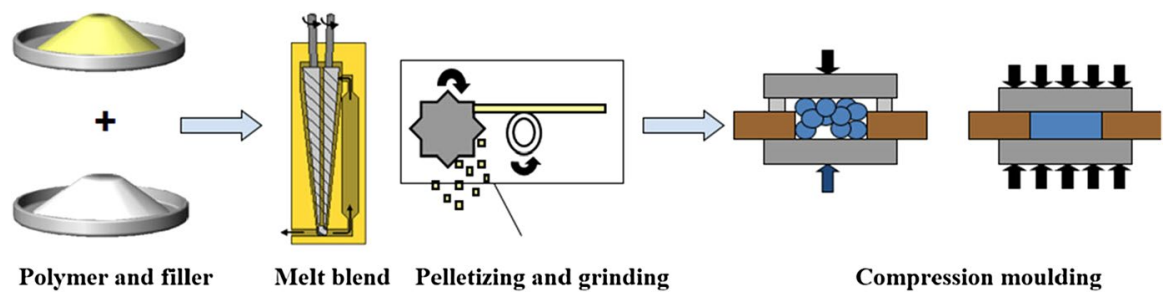

Fig. 6 Preparation of biobased polyamides composites containing boron nitride particles. Reproduced with permission from Ref. [94]

composites were shown to be electrical insulators. Mechanical properties, such as hardness and impact strength, were reduced after addition of the boron nitride filler, but at the same time the thermal properties were improved with increasing filler content [94].

\section{Rice husk ash and nanoclay}

Mechanical properties of composite materials consisting of bioPA 10.10 or bioPA 6.10 and rice husk ash and nanoclay were investigated by Battegazzore et al. Results showed that the addition of rice husk ash results in significant improvement of Young's modulus, reduction of tensile strength and large reduction of deformation at break which may be related to the low efficiency of stresses transferring from matrixes to the filler. The best results of mechanical performance and interactions between polyamides and fillers were obtained after additional incorporation of nanoclay to the composite. Such results were related to the aspect ratio and sub-micrometric exfoliation of montmorillonite [95].

\section{Lignins}

The influence of the lignin type and content on the thermal properties and fire retardancy of biopolyamide 11 composites were investigated by Mandlekar et al. The authors used four types of lignins that differed in resource, purity and chemical nature. The investigations showed that the addition of the sulfonated lignins provided better thermal stability and higher char formation than the addition of kraft lignins (Fig. 7). Additionally, flame retardancy tests showed that the addition of 15 wt $\%$ of both filler types is optimum to improve the flame retardancy [97].

\section{Summary}

A wide range of new biopolyamides with promising mechanical performance and functional properties, but with varied and not fully recognized industrial potential has been developed in the past years from renewable building blocks. The progress in the synthesis of biopolyamides relies on the development in production of biobased platform chemicals, advanced polymerization techniques and understanding 


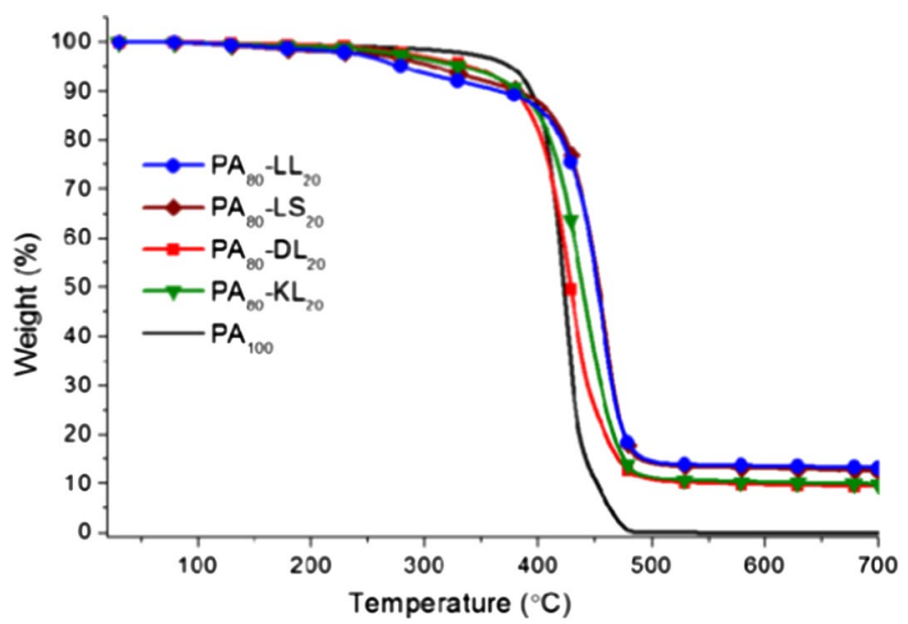

Fig. 7 TG curves, in nitrogen for PA/lignin microcomposite containing $20 \mathrm{wt} \%$ of lignin. Reproduced with permission from Ref. [97]

of structure-property relationship of newly obtained macromolecules. The monomers used for the synthesis of biopolyamides included diacids, diamines, aminoacids and lactams obtained from renewable resources, with a chemical structure analogue to commonly used petrochemical monomers, but also numbers of more sophisticated bio-resourced compounds. The important advantage of bio-based over the petrochemical sourced monomers is that the former often bear functional groups that impart new functional properties to obtained specialty polymers. Making use of biochemicals, a complex and diverse group, is both promising, due to new possible properties of polymers unavailable through petrochemical routes, and challenging due to efficiency and cost issues.

In order to fulfil specific market demands for biopolyamides as an engineering material, where mechanical performance combined with functional properties is of major interest, the chemical approach is supplemented with physical modification of biopolyamides. In the context of composite manufacturing, the main attention was paid to biopolyamides reinforced with natural fibers. That environmentally friendly composite materials offer enhanced mechanical properties including tensile and flexural strength and modulus. However, there are still some challenges in fabrication of bioPAs composites with natural fibers. A relatively low thermal stability of natural fibers in comparison with biopolyamide matrices was the main difficulty in the preparation scheme, which induced surface modification and careful selection of components and processing parameters. Another problem was high water absorption of natural fibers which caused technological difficulties during processing. Thus, chemical modification conducted on the fibers prior to composites processing or using blends of biopolyamides with hydrophobic polyolefines as matrices for biocomposites were applied. The use of hybrid reinforcement composed of natural fibers and synthetic ones was shown as an alternative approach for manufacturing biopolyamide materials with improved thermal and mechanical behavior. Hybrid 
composites are currently a feasible compromise between mechanical properties and the cost, density and environmental aspects. Biopolyamides filled with natural fibers, including cellulosic ones, can be a good choice for structural and high-performance applications, where other sustainable materials do not fulfil demands, such as natural fiber plastic composites (NFPCs) based on polyolefins or polylactide. Biopolyamides modified with functional additives as materials for special applications, e.g., in electronic, packaging or textiles industries, are in the initial phase of development.

Acknowledgements This research work was supported by Polish National Science Centre under the Grant No. UMO/2015/19/B/ST8/01060.

OpenAccess This article is distributed under the terms of the Creative Commons Attribution 4.0 International License (http://creativecommons.org/licenses/by/4.0/), which permits unrestricted use, distribution, and reproduction in any medium, provided you give appropriate credit to the original author(s) and the source, provide a link to the Creative Commons license, and indicate if changes were made.

\section{References}

1. Jang Y-S, Kim B, Shin JH, Choi YJ, Choi S, Song CW, Lee J, Park HG, Lee SY (2012) Biobased production of C2-C6 platform chemicals. Biotechnol Bioeng 109:2437-2459. https://doi. org/10.1002/bit.24599

2. Winnacker M, Rieger B (2016) Biobased polyamides: recent advances in basic and applied research. Macromol Rapid Commun 37:1391-1413. https://doi.org/10.1002/marc.201600181

3. Douka A, Vouyiouka S, Papaspyridi L-M, Papaspyrides CD (2018) A review on enzymatic polymerization to produce polycondensation polymers: the case of aliphatic polyesters, polyamides and polyesteramides. Prog Polym Sci 79:1-25. https://doi.org/10.1016/J.PROGPOLYMSCI.2017.10.001

4. Gorrasi G, Bugatti V, Ussia M, Mendichi R, Zampino D, Puglisi C, Carroccio SC (2018) Halloysite nanotubes and thymol as photo protectors of biobased polyamide 11. Polym Degrad Stab 152:4351. https://doi.org/10.1016/j.polymdegradstab.2018.03.015

5. Otaegi I, Aramburu N, Müller A, Guerrica-Echevarría G (2018) Novel biobased polyamide 410/ polyamide 6/CNT nanocomposites. Polymers (Basel) 10:986. https://doi.org/10.3390/polym10090 986

6. Rashmi BJ, Prashantha K, Lacrampe MF, Krawczak P (2018) Scalable production of multifunctional bio-based polyamide 11/graphene nanocomposites by melt extrusion processes via masterbatch approach. Adv Polym Technol 37:1067-1075. https://doi.org/10.1002/adv.21757

7. Kristufek SL, Wacker KT, Tsao Y-YT, Su L, Wooley KL (2017) Monomer design strategies to create natural product-based polymer materials. Nat Prod Rep 34:433-459. https://doi.org/10.1039/ C6NP00112B

8. Aeschelmann F, Carus M (2015) Biobased building blocks and polymers in the world: capacities, production, and applications-status quo and trends towards 2020. Ind Biotechnol. https://doi. org/10.1089/ind.2015.28999.fae

9. Kuciel S, Kuzniar P, Liber-Kneć A (2012) Polyamides from renewable sources as matrices of short fiber reinforced biocomposites. Polimery 57:627-634. https://doi.org/10.14314/polimery.2012.627

10. Kabasci S (2003) Biobased plastics. Wiley, Chichester

11. Mubofu EB (2016) Castor oil as a potential renewable resource for the production of functional materials. Sustain Chem Process 4:11. https://doi.org/10.1186/s40508-016-0055-8

12. Dasari S, Goud V (2013) Comparative extraction of castor seed oil using polar and non polar solvents. In: Proceedings of national conference on 'Women in Science \& Engineering' (NCWSE 2013), International journal of current engineering and technology special issue 1. SDMCET Dharwad, pp 121-123 
13. Ogunniyi DS (2006) Castor oil: a vital industrial raw material. Bioresour Technol 97:1086-1091. https://doi.org/10.1016/j.biortech.2005.03.028

14. Nangbes JG, Nvau JB, Buba WM, Zukdimma AN (2013) Extraction and characterization of castor (Ricinus communis) seed oil. Int J Eng Sci 2:105-109. https://doi.org/10.1016/j.indcrop.2012.07.022

15. Imankulov N (2012) Preparation and research on properties of castor oil as a diesel fuel additive. Appl Technol Innov 6:30-37. https://doi.org/10.15208/ati.2012.4

16. Harmsen P, Hackmann M, Bos H (2014) Perspective: Green building blocks for bio-based plastics. Biofuels Bioprod Biorefin 8:306-324. https://doi.org/10.1002/bbb

17. Anderson D, Anderson, Dan (2005) A primer on oils processing technology. In: Bailey's industrial oil and fat products. Wiley, Hoboken, pp 1-56

18. Naughton FC (1974) Production, chemistry, and commercial applications of various chemicals from castor oil. J Am Oil Chem Soc 51:65-71. https://doi.org/10.1007/BF00000015

19. Mutlu H, Meier MAR (2010) Castor oil as a renewable resource for the chemical industry. Eur J Lipid Sci Technol 112:10-30. https://doi.org/10.1002/ejlt.200900138

20. Dytham RA, Weedon BCL (1960) Organic reactions in strong alkalis-III. Fission of keto- and hydroxy-acids. Tetrahedron 8:246-260. https://doi.org/10.1016/0040-4020(60)80033-6

21. Diamond MJ, Binder RG, Applewhite TH (1965) Alkaline cleavage of hydroxy unsaturated fatty acids. I. Ricinoleic acid and lesquerolic acid. J Am Oil Chem Soc 42:882-884. https://doi. org/10.1007/BF02541184

22. Jasinska L, Villani M, Wu J, Van Es D, Klop E, Rastogi S, Koning CE (2011) Novel, fully biobased semicrystalline polyamides. Macromolecules 44:3458-3466. https://doi.org/10.1021/ ma200256v

23. Niu W, Draths KM, Frost JW (2002) Benzene-free synthesis of adipic acid. Biotechnol Prog 18:201-211. https://doi.org/10.1021/bp010179x

24. De Guzman D (2013) Verdezyne seeks Asian market for bio-adipic acidlGreen Chemicals Blog. https://greenchemicalsblog.com/2013/06/20/verdezyne-seeks-asian-market-for-bio-adipic-acid/. Accessed 7 May 2017

25. Diamond GM, Murphy V, Boussie TR (2014) Application of high throughput experimentation to the production of commodity chemicals from renewable feedstock. In: Hagemeyer A, Volpe AF (eds) Modern application of high throughput R\&D in heterogeneous catalysis. Bentham Science Publishers, California, pp 288-309

26. Wang M-S, Huang J-C (1994) Nylon 1010 properties and applications. J Polym Eng 13:155-174. https://doi.org/10.1515/POLYENG.1994.13.2.155

27. Qian ZG, Xia XX, Lee SY (2009) Metabolic engineering of Escherichia coli for the production of putrescine: a four carbon diamine. Biotechnol Bioeng 104:651-662

28. Buschke N, Becker J, Schäfer R, Kiefer P, Biedendieck R, Wittmann C (2013) Systems metabolic engineering of xylose-utilizing Corynebacterium glutamicum for production of 1,5-diaminopentane. Biotechnol J 8:557-570. https://doi.org/10.1002/biot.201200367

29. Yan Y, Gooneie A, Ye H, Deng L, Qiu Z, Reifler FA, Hufenus R (2018) Morphology and crystallization of biobased polyamide 56 blended with polyethylene terephthalate. Macromol Mater Eng 303:1800214. https://doi.org/10.1002/mame.201800214

30. Kind S, Neubauer S, Becker J, Yamamoto M, Völkert M, von Abendroth G, Zelder O, Wittmann C (2014) From zero to hero-production of bio-based nylon from renewable resources using engineered Corynebacterium glutamicum. Metab Eng 25:113-123. https://doi.org/10.1016/j. ymben.2014.05.007

31. Frost J (2005) Synthesis of caprolactam from lysine. WO Pat. 2,005,123,669 1:1-10

32. Buntara T, Noel S, Phua PH, Melián-Cabrera I, de Vries JG, Heeres HJ (2011) Caprolactam from renewable resources: catalytic conversion of 5-hydroxymethylfurfural into caprolactone. Angew Chemie 123:7221-7225. https://doi.org/10.1002/ange.201102156

33. Kim K-S, Yu AJ (1979) Copolyamides derived from brassylic acid. J Appl Polym Sci 23:439444. https://doi.org/10.1002/app.1979.070230213

34. An alternative raw material for polyamide 12: Evonik is operating a pilot plant for bio-based $\omega$-amino lauric acid. https://corporate.evonik.de/en/media/search/pages/news-details.aspx?newsi $\mathrm{d}=37328$. Accessed 28 Nov 2018

35. Kolb N, Winkler M, Syldatk C, Meier MAR (2014) Long-chain polyesters and polyamides from biochemically derived fatty acids. Eur Polym J 51:159-166. https://doi.org/10.1016/j.eurpo lymj.2013.11.007 
36. Stempfle F, Quinzler D, Heckler I, Mecking S (2011) Long-chain linear C 19 and C 23 monomers and polycondensates from unsaturated fatty acid esters. Macromolecules 44:4159-4166. https://doi.org/10.1021/ma200627e

37. Bennett C, Mathias LJ (2004) Linear unsaturated polyamides: nylons 6 U18 and 18 U18. Macromol Chem Phys 205:2438-2442. https://doi.org/10.1002/macp.200400351

38. Mutlu H, Meier MAR (2009) Unsaturated PA X,20 from renewable resources via metathesis and catalytic amidation. Macromol Chem Phys 210:1019-1025. https://doi.org/10.1002/macp.20090 0045

39. Walther G, Deutsch J, Martin A, Baumann F-E, Fridag D, Franke R, Köckritz A (2011) $\alpha$,

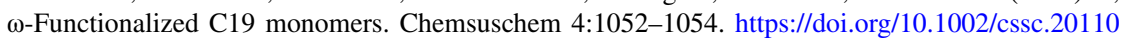
0187

40. Winkler M, Steinbiß M, Meier MAR (2014) A more sustainable Wohl-Ziegler bromination: versatile derivatization of unsaturated FAMEs and synthesis of renewable polyamides. Eur J Lipid Sci Technol 116:44-51. https://doi.org/10.1002/ejlt.201300126

41. Winkler M, Meier MAR (2014) Highly efficient oxyfunctionalization of unsaturated fatty acid esters: an attractive route for the synthesis of polyamides from renewable resources. Green Chem 16:1784-1788. https://doi.org/10.1039/C3GC41921E

42. Türünç O, Firdaus M, Klein G, Meier MAR (2012) Fatty acid derived renewable polyamides via thiol-ene additions. Green Chem 14:2577. https://doi.org/10.1039/c2gc35982k

43. Chen X, Zhong H, Jia L, Ning J, Tang R, Qiao J, Zhang Z (2002) Polyamides derived from piperazine and used for hot-melt adhesives: synthesis and properties. Int J Adhes Adhes 22:75-79. https:// doi.org/10.1016/S0143-7496(01)00039-2

44. Hablot E, Donnio B, Bouquey M, Avérous L (2010) Dimer acid-based thermoplastic bio-polyamides: Reaction kinetics, properties and structure. Polymer (Guildf) 51:5895-5902. https://doi. org/10.1016/j.polymer.2010.10.026

45. Gandini A, Lacerda TM (2015) From monomers to polymers from renewable resources: Recent advances. Prog Polym Sci 48:1-39. https://doi.org/10.1016/j.progpolymsci.2014.11.002

46. Bou JJ, Rodriguez-Galan A, Munoz-Guerra S (1993) Optically active polyamides derived from L-tartaric acid. Macromolecules 26:5664-5670. https://doi.org/10.1021/ma00073a020

47. Sousa AF, Vilela C, Fonseca AC, Matos M, Freire CSR, Gruter G-JM, Coelho JFJ, Silvestre AJD (2015) Biobased polyesters and other polymers from 2,5-furandicarboxylic acid: a tribute to furan excellency. Polym Chem 6:5961-5983. https://doi.org/10.1039/C5PY00686D

48. Jiang Y, Maniar D, Woortman AJJ, Alberda van Ekenstein GOR, Loos K (2015) Enzymatic polymerization of furan-2,5-dicarboxylic acid-based furanic-aliphatic polyamides as sustainable alternatives to polyphthalamides. Biomacromol 16:3674-3685. https://doi.org/10.1021/acs.biomac.5b011 72

49. Ali MA, Tateyama S, Kaneko T (2014) Syntheses of rigid-rod but degradable biopolyamides from itaconic acid with aromatic diamines. Polym Degrad Stab 109:367-372. https://doi.org/10.1016/j. polymdegradstab.2014.05.031

50. Ali MA, Tateyama S, Oka Y, Kaneko D, Okajima MK, Kaneko T (2013) Syntheses of high-performance biopolyamides derived from itaconic acid and their environmental corrosion. Macromolecules 46:3719-3725. https://doi.org/10.1021/ma400395b

51. Wang Z, Wei T, Xue X, He M, Xue J, Song M, Wu S, Kang H, Zhang L, Jia Q (2014) Synthesis of fully bio-based polyamides with tunable properties by employing itaconic acid. Polymer (Guildf) 55:4846-4856. https://doi.org/10.1016/J.POLYMER.2014.07.034

52. Wang Q, Shao ZZ, Yu TY (1996) The synthesis and characterization of polyethylene succinamide (polyamide 24). Polym Bull 36:659-665. https://doi.org/10.1007/BF00338627

53. Dreyfuss P, Keller A (1973) Invariance of the long spacing-crystallization temperature dependence of polyamides precipitated from solution. J Polym Sci Part A-2 Polym Phys 11:193-200. https://doi. org/10.1002/pol.1973.180110201

54. Gaymans RJ, Van Utteren TEC, Van Den Berg JWA, Schuyer J (1977) Preparation and some properties of nylon 46. J Polym Sci Polym Chem Ed 15:537-545. https://doi.org/10.1002/pol.1977.17015 0303

55. Winkler M, Raupp YS, Ko LAM, Wagner HE, Meier MAR (2014) Modified poly( $\varepsilon$-caprolactone)s: an efficient and renewable access via Thia-Michael addition and Baeyer-Villiger oxidation. Macromolecules 47:2842-2846. https://doi.org/10.1021/ma500381n 
56. Winnacker M, Sag J, Tischner A, Rieger B (2017) Sustainable, stereoregular, and optically active polyamides via cationic polymerization of $\varepsilon$-lactams derived from the terpene $\beta$-pinene. Macromol Rapid Commun 38:1-7. https://doi.org/10.1002/marc.201600787

57. van Velthoven JLJ, Gootjes L, Noordover BAJ, Meuldijk J (2015) Bio-based, amorphous polyamides with tunable thermal properties. Eur Polym J 66:57-66. https://doi.org/10.1016/j.eurpo lymj.2015.01.040

58. Sun Z, Wang X, Guo F, Jiang C, Pan Q (2016) Isothermal and nonisothermal crystallization kinetics of bio-sourced nylon 69. Chinese J Chem Eng 24:638-645. https://doi.org/10.1016/J.CJCHE 2015.12.021

59. Fukuda Y, Sasanuma Y (2018) Computational characterization of nylon 4, a biobased and biodegradable polyamide superior to nylon 6. ACS Omega 3:9544-9555. https://doi.org/10.1021/ acsomega.8b00915

60. Jasinska-Walc L, Villani M, Dudenko D, Van Asselen O, Klop E, Rastogi S, Hansen MR, Koning CE (2012) Local conformation and cocrystallization phenomena in renewable diaminoisoididebased polyamides studied by FT-IR, solid state NMR, and WAXD. Macromolecules 45:27962808. https://doi.org/10.1021/ma300133d

61. Rwei S-P, Ranganathan P, Chiang W-Y, Lee Y-H (2018) Synthesis and characterization of copolyamides derived from novel aliphatic bio-based diamine. J Appl Polym Sci 135:46878. https:// doi.org/10.1002/app.46878

62. Eltahir YA, Saeed HAM, Xia Y, Yong H, Yimin W (2015) Mechanical properties, moisture absorption, and dyeability of polyamide 5,6 fibers. J Text Inst. https://doi.org/10.1080/00405 000.2015 .1020678

63. Martino L, Basilissi L, Farina H, Ortenzi MA, Zini E, Di Silvestro G, Scandola M (2014) Biobased polyamide 11: Synthesis, rheology and solid-state properties of star structures. Eur Polym J 59:69-77. https://doi.org/10.1016/j.eurpolymj.2014.07.012

64. Samanta S, He J, Selvakumar S, Lattimer J, Ulven C, Sibi M, Bahr J, Chisholm BJ (2013) Polyamides based on the renewable monomer, 1,13-tridecane diamine II: Synthesis and characterization of nylon 13,6. Polymer (Guildf) 54:1141-1149. https://doi.org/10.1016/j.polym er.2012.12.034

65. Iribarren I, Alemán C, Bou JJ, Muñoz-Guerra S (1996) Crystal structures of optically active polyamides derived from di-O-methyl-1-tartaric acid and 1,n-alkanediamines: a study combining energy calculations, diffraction analysis, and modeling simulations. Macromolecules 2:2. https:// doi.org/10.1021/ma951394v

66. Muñoz-Guerra S, Fernández CE, Benito E, Marín R, García-Martín MG, Bermúdez M, Galbis JA (2009) Crystalline structure and crystallization of stereoisomeric polyamides derived from arabinaric acid. Polymer (Guildf) 50:2048-2057. https://doi.org/10.1016/J.POLYM ER.2009.02.014

67. Kim SJ, Kim BJ, Jang DW, Kim SH, Park SY, Lee J-H, Lee S-D, Choi DH (2001) Photoactive polyamideimides synthesized by the polycondensation of azo-dye diamines and rosin derivative. J Appl Polym Sci 79:687-695. https://doi.org/10.1002/1097-4628(20010124)79:4\%3c687:AIDAPP130\%3e3.0.CO;2-9

68. Yao F, Wu Q, Lei Y, Guo W, Xu Y (2008) Thermal decomposition kinetics of natural fibers: activation energy with dynamic thermogravimetric analysis. Polym Degrad Stab 93:90-98. https ://doi.org/10.1016/j.polymdegradstab.2007.10.012

69. John MJ, Thomas S (2008) Biofibres and biocomposites. Carbohydr Polym 71:343-364. https:// doi.org/10.1016/j.carbpol.2007.05.040

70. Saheb N, Jog J (2015) Natural fiber polymer composites : a review. Adv Polym Technol 2329:351-363. https://doi.org/10.1002/(SICI)1098-2329(199924)18

71. Madsen B, Gamstedt EK (2013) Wood vs. plant fibers : similarities and differences in composite applications. Adv Mater Sci Eng 2013:1-43

72. Bledzki Sperber F (2002) Natural and wood fibre reinforcement in polymers. Smithers Rapra Publishing, Akron

73. Hofstetter K, Hellmich C, Eberhardsteiner J (2005) Development and experimental validation of a continuum micromechanics model for the elasticity of wood. Eur J Mech A/Solids 24:10301053. https://doi.org/10.1016/j.euromechsol.2005.05.006

74. Zierdt P, Theumer T, Kulkarni G, Däumlich V, Klehm J, Hirsch U, Weber A (2015) Sustainable wood-plastic composites from bio-based polyamide 11 and chemically modified beech fibers. Sustain Mater Technol 6:6-14. https://doi.org/10.1016/j.susmat.2015.10.001 
75. Armioun S, Panthapulakkal S, Scheel J, Tjong J, Sain M (2016) Biopolyamide hybrid composites for high performance applications. J Appl Polym Sci 133:1-9. https://doi.org/10.1002/ app.43595

76. Armioun S, Panthapulakkal S, Scheel J, Tjong J, Sain M (2016) Sustainable and lightweight biopolyamide hybrid composites for greener auto parts. Can J Chem Eng 94:2052-2060. https:// doi.org/10.1002/cjce. 22609

77. Nishitani Y, Yamanaka T (2016) Thermal properties of hemp fiber reinforced plant-derived polyamide biomass composites and their dynamic viscoelastic properties in molten state. In: El-Amin $\mathrm{M}$ (ed) Viscoelastic and viscoplastic materials. INTECH, pp 52-79

78. Feldmann M, Bledzki AK (2014) Bio-based polyamides reinforced with cellulosic fibres-processing and properties. Compos Sci Technol 100:113-120. https://doi.org/10.1016/j.compscitec h.2014.06.008

79. Hablot E, Matadi R, Ahzi S, Vaudemond R, Ruch D, Avérous L (2010) Yield behaviour of renewable biocomposites of dimer fatty acid-based polyamides with cellulose fibres. Compos Sci Technol 70:525-529. https://doi.org/10.1016/J.COMPSCITECH.2009.12.009

80. Leszczyńska A, Kiciliński P, Pielichowski K (2015) Biocomposites of polyamide 4.10 and surface modified microfibrillated cellulose (MFC): influence of processing parameters on structure and thermomechanical properties. Cellulose 22:2551-2569. https://doi.org/10.1007/s 1057 $0-015-0657-4$

81. Oliver-Ortega H, Granda LA, Espinach FX, Mendez JA, Julian F, Mutjé P (2016) Tensile properties and micromechanical analysis of stone groundwood from softwood reinforced bio-based polyamide11 composites. Compos Sci Technol 132:123-130. https://doi.org/10.1016/j.comps citech.2016.07.004

82. Oliver-Ortega H, Granda LA, Espinach FX, Delgado-Aguilar M, Duran J, Mutjé P (2016) Stiffness of bio-based polyamide 11 reinforced with softwood stone ground-wood fibres as an alternative to polypropylene-glass fibre composites. Eur Polym J 84:481-489. https://doi.org/10.1016/j. eurpolymj.2016.09.062

83. Le Duigou A, Bourmaud A, Gourier C, Baley C (2016) Multi-scale shear properties of flax fibre reinforced polyamide 11 biocomposites. Compos Part A Appl Sci Manuf 85:123-129. https:// doi.org/10.1016/j.compositesa.2016.03.014

84. Boumbimba RM, Wang K, Hablot E, Bahlouli N, Ahzi S, Avérous L (2017) Renewable biocomposites based on cellulose fibers and dimer fatty acid polyamide: Experiments and modeling of the stress-strain behavior. Polym Eng Sci 57:95-104. https://doi.org/10.1002/pen.24390

85. Nikiforov AA, Vol'fson SI, Okhotina NA, Rinberg R, Hartmann T, Kroll L (2017) Mechanical properties of the compositions based on biopolyamide-1010 modified by carbon, glass, and cellulose chopped fibers. Russ Metall 2017:279-282. https://doi.org/10.1134/s0036029517040152

86. Pickering KL, Efendy MGA, Le TM (2016) A review of recent developments in natural fibre composites and their mechanical performance. Compos Part A Appl Sci Manuf 83:98-112. https ://doi.org/10.1016/J.COMPOSITESA.2015.08.038

87. Faruk O, Bledzki AK, Fink HP, Sain M (2014) Progress report on natural fiber reinforced composites. Macromol Mater Eng 299:9-26. https://doi.org/10.1002/mame.201300008

88. Pagacz J, Leszczynska A, Modesti M, Boaretti C, Roso M, Malka I, Pielichowski K (2015) Thermal decomposition studies of bio-resourced polyamides by thermogravimetry and evolved gas analysis. Thermochim Acta 612:40-48. https://doi.org/10.1016/j.tca.2015.05.003

89. Pagacz J, Raftopoulos KN, Leszczyńska A, Pielichowski K (2016) Bio-polyamides based on renewable raw materials: Glass transition and crystallinity studies. J Therm Anal Calorim 123:1225-1237. https://doi.org/10.1007/s10973-015-4929-x

90. Leszczyńska A, Stafin K, Pagacz J, Mičušík M, Omastova M, Hebda E, Pielichowski J, Borschneck D, Rose J, Pielichowski K (2018) The effect of surface modification of microfibrillated cellulose (MFC) by acid chlorides on the structural and thermomechanical properties of biopolyamide 4.10 nanocomposites. Ind Crops Prod 116:97-108. https://doi.org/10.1016/j.indcr op. 2018.02 .022

91. Hablot E, Matadi R, Ahzi S, Avérous L (2010) Renewable biocomposites of dimer fatty acidbased polyamides with cellulose fibres: thermal, physical and mechanical properties. Compos Sci Technol 70:504-509. https://doi.org/10.1016/j.compscitech.2009.12.001

92. Kuciel S, Kuÿnia P, Jakubowska P (2016) Properties of composites based on polyamide 10. 10 reinforced with carbon fibers. Polimery 61:106-112 
93. Kuciel S, Kuzniar P, Bogucki R (2014) Kompozyty na osnowie biopoliamidu z maczka lupin orzecha modyfikowane powierzchniowo nanoczastkami srebra. Przetwórstwo Tworzyw 6:507-511

94. Ghaffari Mosanenzadeh S, Liu MW, Osia A, Naguib HE (2015) Thermal composites of biobased polyamide with boron nitride micro networks. J Polym Environ 23:566-579. https://doi. org/10.1007/s10924-015-0733-8

95. Battegazzore D, Salvetti O, Frache A, Peduto N, De Sio A, Marino F (2016) Thermo-mechanical properties enhancement of bio-polyamides (PA10.10 and PA6.10) by using rice husk ash and nanoclay. Compos Part A Appl Sci Manuf 81:193-201. https://doi.org/10.1016/j.composites a.2015.11.022

96. Hajibeygi M, Omidi-Ghallemohamadi M (2017) One-step synthesized azo-dye modified Mg-Al LDH reinforced biobased semi-aromatic polyamide containing naphthalene ring; study on thermal stability and optical properties. J Polym Res. https://doi.org/10.1007/s10965-017-1212-9

97. Mandlekar N, Cayla A, Rault F, Giraud S, Salaün F, Malucelli G, Guan J (2017) Thermal stability and fire retardant properties of polyamide 11 microcomposites containing different lignins. Ind Eng Chem Res 56:13704-13714. https://doi.org/10.1021/acs.iecr.7b03085

98. Ferry L, Sonnier R, Lopez-Cuesta JM, Petigny S, Bert C (2017) Thermal degradation and flammability of polyamide 11 filled with nanoboehmite. J Therm Anal Calorim 129:1029-1037. https://doi. org/10.1007/s10973-017-6244-1

Publisher's Note Springer Nature remains neutral with regard to jurisdictional claims in published maps and institutional affiliations. 